San Antonio Review • San Antonio Review (Issue 2 | Winter 2019)

\title{
Kid Brother Dropout
}

\section{Kevin Ridgeway}

Published on: May 01, 2019

Updated on: Aug 02, 2020

License: Creative Commons Attribution 4.0 International License (CC-BY 4.0). 
I wanted to be just

like my older brother; tired of being known as just Sean's kid brother, so I wanted to be his equal or surpass him. I auditioned for the same role he won awards for my senior year but I lost the role to a friend. And I was passed over by my brother's college, an inferior little man in the shadows of the great one I must bow to but instead I

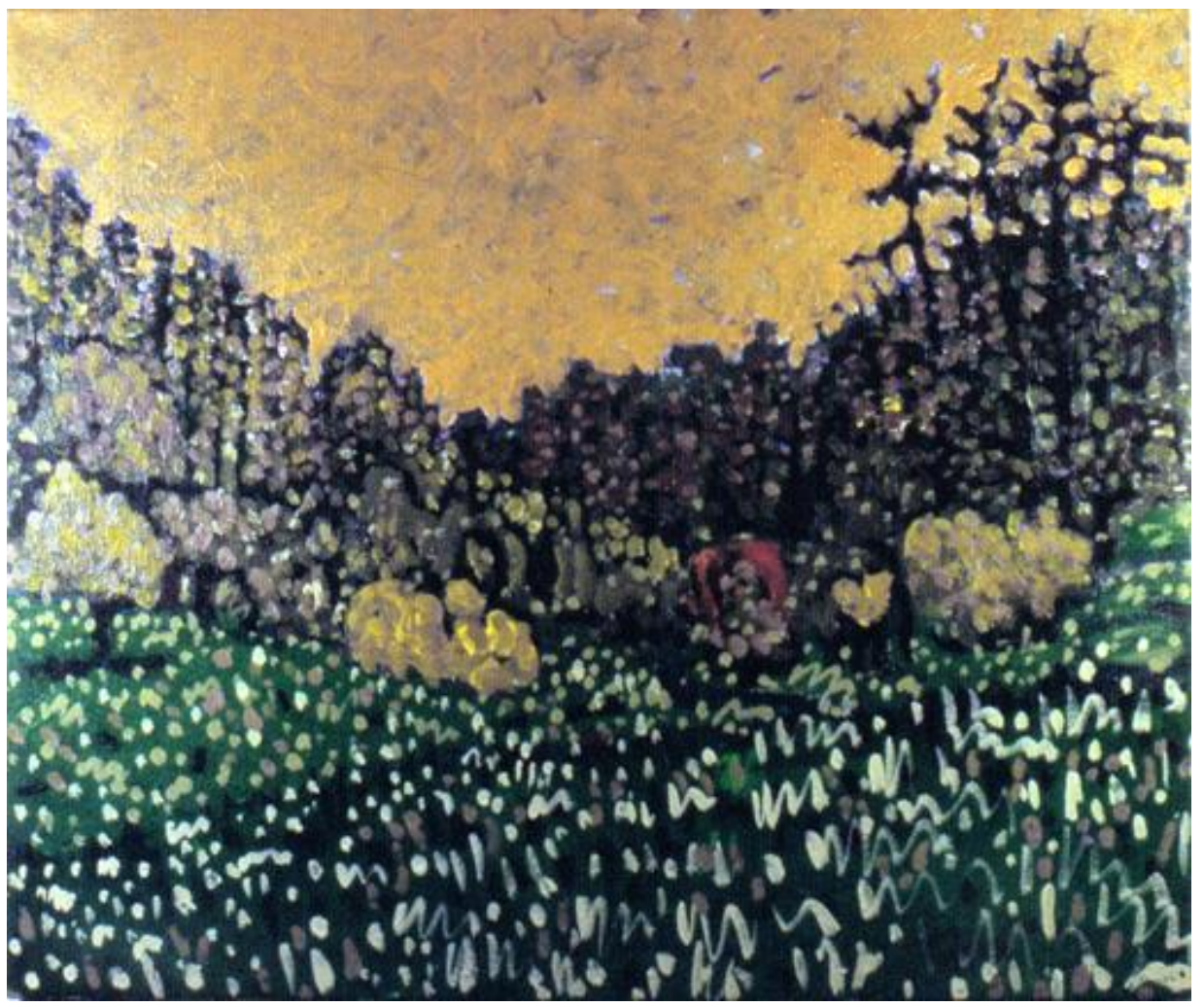

Painting by Brianna Keeper

rebelled and became a bearded freak in the green mountains of Vermont, doing drugs and fueling my damaged little ego with a new frontier of possibilities big brother could never dream of after a slight bit of chemical brain damage freed me of the need to compare myself to him or want to kick him in the eye with my cowboy boots wrestling him on the living room carpet back in 1984 when I fought dirty and tried to bite his dick off, still fighting dirty to this day in order to overcome my lack of an identity after years of not knowing who to be as the youngest in a family of worldwide superstars.

Kevin Ridgeway is the author of Too Young to Know (Stubborn Mule Press). His work has recently appeared in Slipstream, Chiron Review, Nerve Cowboy, Main Street Rag, The American Journal of Poetry, The Cape Rock, Trailer Park Quarterly and So it Goes: The Literary Journal of the Kurt Vonnegut Memorial Library. He lives and writes in Long Beach, CA. 